\title{
Fusion of lower central and lateral incisor in conjugation of a talon's cusp: A case report.
}

\author{
Dr. Mylavarapu Krishna Sagar ${ }^{1}$, Dr.Alok Avinash ${ }^{2}$, Dr.Lavinder Kaur Gill ${ }^{3}$, \\ Dr.Brij Kumar ${ }^{1}$ \\ 1.Final Year Post-Graduate Student, Department Of PedodonticsAnd Preventive Dentistry, Rungta Dental \\ College, Bhilai, Chhattisgarh, India \\ 2. Reader, Department Of PedodonticsAnd Preventive Dentistry, Rungta Dental College, Bhilai, Chhattisgarh, \\ India \\ 3.Senior Lecturer, Department Of Pedodontics And Preventive Dentistry, Rungta Dental College, Bhilai, \\ Chhattisgarh, India
}

Abstract:Talon's cusp is a properly delineated additional cusp which is said to arise due to evagination on the tooth surface even before the calcification has taken place. Hence it is also known as dens evaginatus. Fusion is a condition wherein the crowns of two separate teeth are seen to have joined togetherduring the time of crown development. The present article describes a case where in both the presence of talon's cusp as well as fusion is seen.

Mesh Keywords:Talon's cusp, Dens Evaginatus, Fusion,

\section{Introduction}

Talon cusp has been defined as a supernumerary accessory talon-shaped cusp projecting from the lingual or facial surface of the crown of a tooth and extending for at least half the distance from the cementenamel junction to the incisal edge. ${ }^{1}$ Mitchell in 1892 was the first person ever to record the talon's cusp. The addition cusp which was present on the lingual surface of the maxillary central incisor of a female patient was described by her as 'a process of a horn-like shape curving from the base downward to the cutting edge'.,3

The term Talon's cusp was first given by Mellor and Ripa in $1970 .{ }^{4}$ Fusion of teeth is a rare developmental anomaly that arises from the embryogenic union of two teeth which originates from two or more tooth germs. ${ }^{5,6}$ Even thought the exact etiology of fusion is not completely clear, major factor thought to be causative of fusion is the pressure and the physical forces which produce close contact between two developing tooth buds. Other than that, trauma, environmental factors and genetic factors are also assumed to be the contributing factors. ${ }^{7,9,10}$

This article presents a case in which both Talons cusp as well as fusion is observed.

\section{Case Report}

A 12 year old male patient reported to Department of Pedodontics and Preventive Dentistry with a complaint of pain in the lower right and left region of jaw. The patient's medical and family history was not significant. General examinations did not reveal any aberrancy. On local examination, there was finding of irreversible pulpitis with mandibular right and left first molar for which endodontic therapy was advised.During the regular endodontic therapy of the mandibular left first molar, the abnormality in the mandibular left central and lateral incisor was accidently detected (Fig 1).

Close clinical examination showed an eagle like extension on the lingual aspect between the mandibular left central and lateral incisor indicative of a presence of a talon's cusp (Fig 2).

And in addition to the extension, there was presence of a complete conjoint of the mandibular left central and lateral incisor (Fig 2 and 3).

Radiograph was taken with respect to the mandibular left central and lateral incisor. Radiograph showed radio-opaque area between the crown portion of mandibular left central and lateral incisor and no presence of inter-dental space is seen suggestive of fusion of both the teeth. (Fig 4)

\section{Discussion}

Talon cusp is an unusual and a rare abnormality which most frequently affects the maxillary permanent incisor. It comprises of enamel, dentine and sometimes varying quantity of pulp. ${ }^{11,12}$. Hattabet al ${ }^{13}$ gave the classification of talon's cusp based on the degree of formation and extension and divided talon's cusps into three categories.

These are: 
- Type 1 (True talon): A well-delineated additional cuspthat predominantly projects from the palatal or lingualsurface of an anterior tooth and extends half wayfrom cementoenamel junction to the incisal edge.

- Type 2 (Semi talon): An additional cusp of a millimetre or more but extending less than half the distance fromcementoenamel junction to incisal edge. It may blendwith palatal surface or strand away from the crown.

- Type 3 (Trace talon): Enlarged cingulum and may presentas conical bifid or tubercle shaped.

According to the above given classification, we graded our case as a Type 1 talon cusp. It was difficult to determine the extent of pulp tissue in the anomalous cusp due to superimposition of the cusp over the main teeth.

Fusion of teeth is very often confused with gemination. Fusion takes place when two teeth buds join with each other whereas on the other hand, gemination happens from the attempted division of one tooth bud into two. ${ }^{14}$ Fusion between two teeth always involves dentin and may result in an abnormally large tooth than normal and the union of both crowns or only of the roots. ${ }^{14,15}$

\section{Management}

The management of talon's cusp varies according to every case. No treatment is indicated in a small asymptomatic talon's cusp. A large anomalous cusp poses clinical problems such as occlusal interference, displacement of the affected tooth, irritation of the tongue during the speech and mastication, carious lesion in the developmental grooves that delineate the cusp, pulpal necrosis, periapical pathosis, attrition of the opposing tooth and periodontal problems due to excessive occlusal forces. ${ }^{16}$ In such cases, fissure sealing and application of composite restoration can be done if the problems are not severe. If they pose a serious problem, then complete removal of cusp is done along with the pulp extirpation and root canal therapy. ${ }^{17}$

Treatment of fused teeth also differs according to every case. If there is carious involvement, no special treatment is required. General advices on preventive procedures are given to the children and their parents. ${ }^{18}$ Restorative procedures are indicated in case of carious exposure but not involving the pulp and endodontic treatment in case of pulpal exposure. ${ }^{19,20}$

In the present case, the patient was totally asymptomatic so no treatment procedure was carried out with respect to mandibular left central and lateral incisor. The patient's endodontic therapy with the mandibular right and left first molars was done followed by prosthetic restoration with each of them.

\section{Conclusion}

All in all, both talon's cusp as well as fusion are relatively rare entities individually with the treatment differing to every other case. The combination of both the anomalies is even more rarer, although the treatment would be pretty much the same as that of the anamolaies individually found.

\section{References}

[1]. Thakur S, Gupta R, Thakur NS, Gupta M. Facial talon cusp on permanent maxillary canine: a rare dental anomaly. Eur J General Dentist 2013;2(3):324-327

[2]. Mitchell WH. Case report. Dent Cosmos 1892;34:1036.

[3]. Jeevarathan J, Deepti A, Muthu MS, Sivakumar N, Soujanya K. Labial and lingual talon cusps of a primary lateral incisor: a case report. Pediatr Dent 2005;27(4):303-306.

[4]. Dumancic J, Kaic Z, Tolj M, Jankovic B. Talon Cusp: a literature review and case report. ActaStomatol Croat 2006;40(2): 169-74.

[5]. A. Kne`zevi'c, S. Travan, Z. Tarle, J. 'Sutalo, B. Jankovi'c, and I. Ciglar, Double tooth.Collegium Antropologicum 2002;26 (2):667-72,

[6]. M. K. Caroll, "Fusion and Gemination in alternate dentitions," Oral Surgery OralMedicine and Oral Pathology 1990; $69(5): 655$.

[7]. R. J. Lowell and A. L. Solomon, "Fused teeth," Journal of the American Dental Association 1964; 68:762.

[8]. W. G. Shafer, M. K. Hine, and B. M. Levy, A Textbook of Pathology, WB Saunders, Philadelphia, Pa, USA, 4th edition, 1983.

[9]. C. L. Mader, Fusion of teeth.The Journal of the American Dental Association 1979; 98(1):62-64.

[10]. E. Moody and L. B. Montgomery.Hereditary tendencies in tooth formation.The Journal of the American Dental Association 1934; 21:1774-76,

[11]. Shafer WG, Hine MK, Levy BM. A Textbook of Oral Pathology. 3rd ed. Philadelphia: W.B. Saunders Co; 1974. p. 38.

[12]. Dash JK, Sahoo PK, Das SN. Talon cusp associated with other dental anomalies: A case report. Int J Paediatr Dent 2004;14:295300 .

[13]. Hattab FN, Yassin OM, al-Nimri KS. Talon cusp in permanent dentition associated with other dental anomalies: Review of literature and reports of seven cases. ASDC J Dent Child 1996;63:368-76.

[14]. Gadimli C, Sari Z. Interdisciplinary treatment of a fused lower premolar with supernumerary tooth. Eur J Dent2011;5:349-353.

[15]. Rotstein I, Moshonov J, Cohenca N. Endodontic therapy for a fused mandibular molar. Endod Dent Traumatol1997;13:149-151.

[16]. Shafer WG, Hine MK, Levy BM. Developmental disturbancesof oral and paraoral structures. In: Sivapathsundaram B, Rajendran R, editors. A Textbook of the Oral Pathology. 5th ed. New Delhi: Elsevier; 2008. p. 3-112.

[17]. $\quad$ Pledger DM, Roberts GJ. Talon cusp: Report of a case. Br Dent J 1989;167:171-3

[18]. Alvarez I, Creath CJ. Radiographic considerations for supernumerary tooth extraction: report of case. ASDC J Dent Child. 1995; 62:141-4.

[19]. Knapp JF, McMahon JI. Treatment of triple tooth: report of case. J Am Dent Assoc. 1984; 109:725-7.

[20]. Santos LM, Forte FD, Rocha MJ. Pulp therapy in a maxillary fused primary central incisor--report of a case. Int J Paediatr Dent. $2003 ; 13: 274-8$. 


\section{LEGEND OF FIGURES}

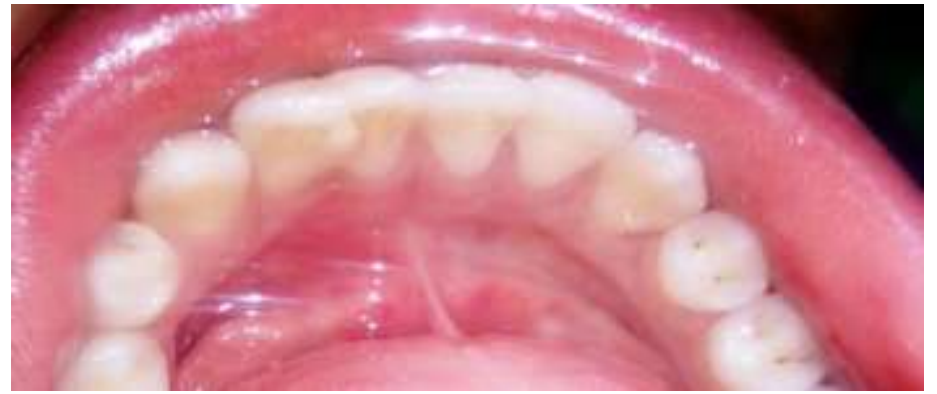

Figure 1

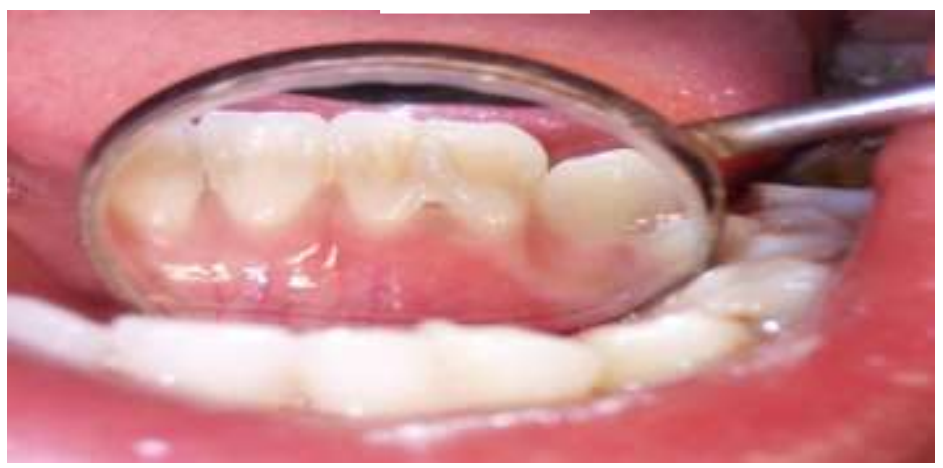

Figure 2

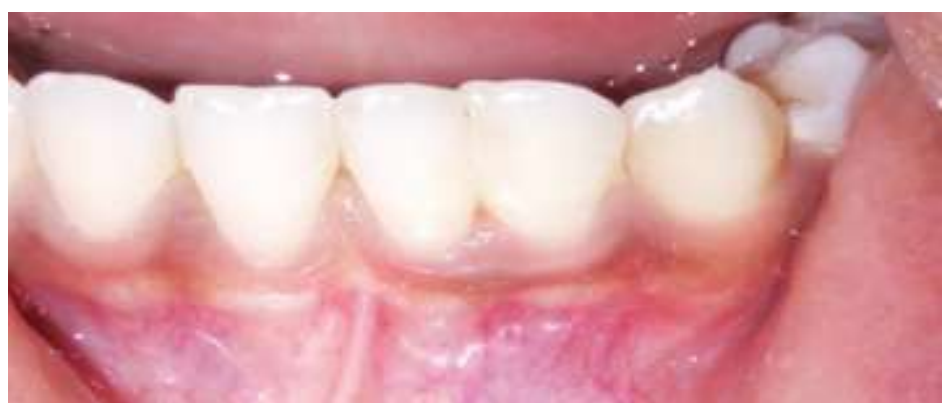

Figure 3

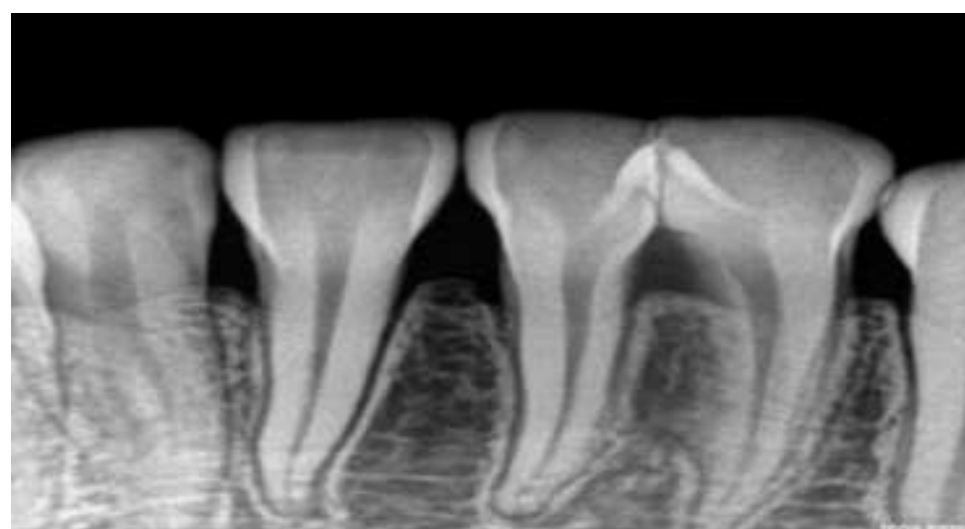

Figure 4

Figure $1 \rightarrow$ Clinical photograph showing the abnormality detected with 31 and 32 .

Figure $2 \rightarrow$ Close up photograph of the Talon's cusp detected lingually.

Figure $3 \rightarrow$ Fusion of 31 and 32 .

Figure $4 \rightarrow$ Radiograph showing Fusion of 31 and 32 